\title{
The Effects of Sorting on the Aluminium Recycling Process in a Rising Demand Market
}

\author{
H. Rodrigues ${ }^{1,2}$, F. Margarido ${ }^{1,2}$, C. A. Nogueira ${ }^{3}$ \\ ${ }^{1}$ DEM, Instituto Superior Técnico, IST (Univ. Lisbon) \\ 1049-001 Lisboa, Portugal \\ ${ }^{2}$ IST, IN+ - Center for Innovation, Technology and Policy Research (Univ. Lisboa) \\ helder.rodrigues@tecnico.ulisboa.pt; fernanda.margarido@tecnico.ulisboa.pt \\ ${ }^{3}$ Laboratório Nacional de Energia e Geologia, I.P. (LNEG) \\ 1649-038 Lisboa, Portugal \\ carlos.nogueira@lneg.pt
}

\begin{abstract}
In this paper, the sustainability of the current approach to aluminium recycling is assessed. Starting with a forecast of aluminium demand, the evolution of the scrap availability through the next decades is foreseen. The current methods to recycle aluminium are described, and a critical view on energy requirements for secondary aluminium production is given. Finally, the potential benefits of sorting aluminium alloys are addressed. The Al market owes its growth to the potential advantages presented in the use phase either in construction, automotive or packaging industries. This will lead to a rise in the end of life scrap and it is foreseen that a scrap surplus will occur within 10 years, if the current approach to recycling continues. Sorting will help increase the value of scrap and avoid its surplus. Nevertheless, an increase in Al scrap collection rates is also crucial because sorting by itself, will not decrease the primary aluminium demand. By 2030, scrap will likely fulfill more than $30 \%$ of the Al demand, but only with new solutions for recycling may this potential be achieved.
\end{abstract}

Keywords: aluminium, wrought, cast, demand, supply, primary, recycling, sustainability.

\section{Introduction}

Aluminium is the third most abundant element on earth's crust. It can be found in bauxite ores, as alumina $\left(\mathrm{Al}_{2} \mathrm{O}_{3}\right)$, which after being purified, is reduced to $\mathrm{Al}$ by electrolysis. However, this is a highly energy intensive process which makes primary $\mathrm{Al}$ expensive in comparison to other materials. These make aluminium a material with a reliable supply capability for economy but also a concern in terms of energy.

Due to its properties, many successful applications for aluminium were found in recent decades. Pure $\mathrm{Al}$ is very soft, however if alloyed with small quantities of other chemical elements, mechanical strength increases, with a negligible increase in density. Aluminium alloys possess a combination of properties, namely: strength, lightness and corrosion resistance. These are properties of great use in industries such as construction, automotive and packaging, which together account for two thirds of Al demand nowadays. This multiplication of applications leads to a significant rise in demand followed by a growth in scrap production.

Its abundance and properties make it a viable option to tackle the environmental challenges faced nowadays. The energy needed to produce aluminium set a big question mark in Al potential, although theoretically these high energy requirement does not hold for secondary aluminium production. Nonetheless, rather than taking this advantage of secondary $\mathrm{Al}$ for granted, a critical assessment of the global chain to fulfil future $\mathrm{Al}$ demand is of utmost importance, in order to foresee potential problems and act towards a self-sustainable Al supply chain.

\section{Aluminium Demand}

In order to assess if the current $\mathrm{Al}$ recycling model lacks sustainability, it is important to understand how $\mathrm{Al}$ needs have been evolving and how they are expected to evolve in the next decades. As, in general, all main industries are under great pressure to improve environmental results, new solutions need to be explored. Both automotive and construction industry are great examples, due to the changes they are facing and their high material consumption. 


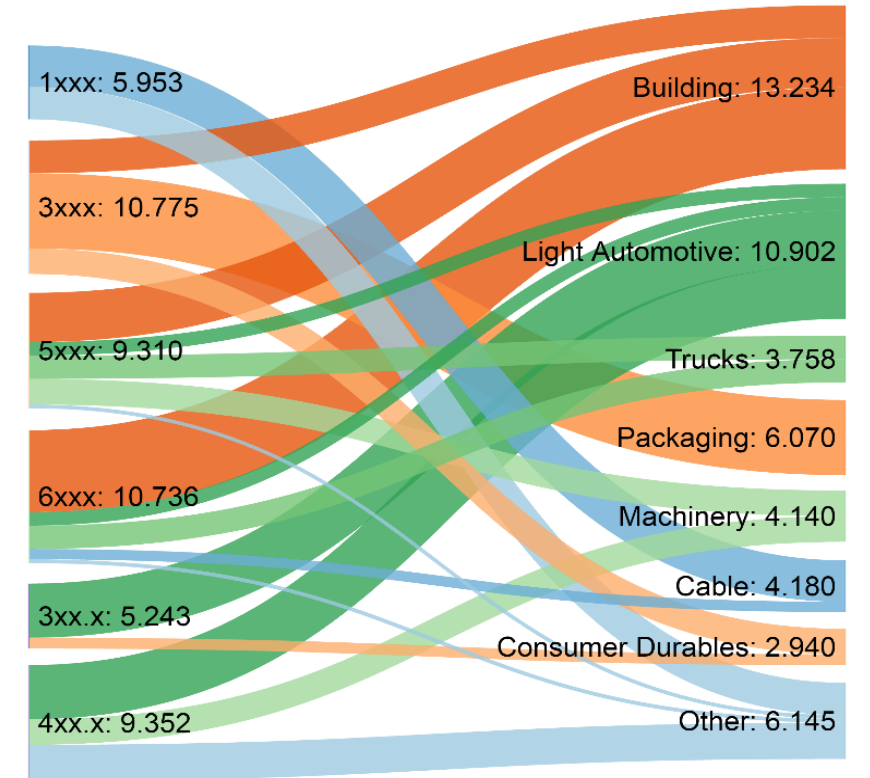

(a)

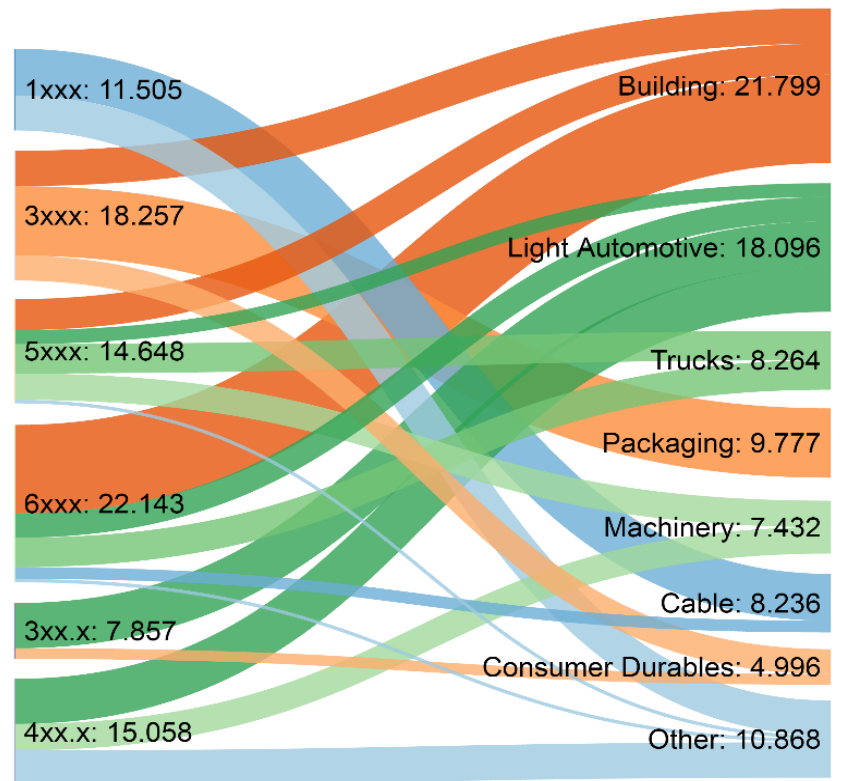

(b)

Fig. 1: Alloys allocated to sectors (in Mt) (a) 2010; (b) by 2030.

The most widely used metal in automotive industry, steel, is three times heavier than aluminium. Required efficiency improvements led to weight reduction needs, which makes aluminium a serious candidate to replace steel in several applications. Furthermore, a penetration of electric vehicles in a near future is expected [1]. Current batteries cannot compete in terms of energy storage with fossil fuels, and this stresses even more the need for weight reduction, in order to improve their autonomy. Additionally, this dictates a faster growth of wrought alloys than cast, as electric vehicles do not need internal combustion engines (cast alloys). The use of plastics and composites is also an alternative, but these present a low recyclability compared to aluminium. Although this is an environmental issue everywhere, for the particular example of European Union, there are also recycling and reuse targets to reach for end of life vehicles (ELV). And as it is known a metal can be recycled over and over not losing its properties, provided that the composition does not change. The growing importance of wrought alloys can be seen in Figure 1, as in 20 years its share in the total $\mathrm{Al}$ demand is expected to go from $71 \%$ to $75 \%$. Demand distribution by sectors was obtained on World of Aluminum database [2], being the main alloys usage by sector computed by the authors. Also on Figure 2 this trend is noticeable, since growth of wrought alloys is clear and cast alloys tend to go almost flat. But other industries are also using aluminium, for example, the construction industry is using more and more extrusion profiles for window frames and internal divisions. Construction together with the automotive industry (Light automotive and Trucks) will be responsible for 56\% of Al demand by 2030 (Figure 1). In packaging industry the increase use of $\mathrm{Al}$ cans is also foreseen. In conduction wires applications, aluminum is also starting to be a rather viable option in the competition with copper, because copper's price is around two fold higher. Although the aerospace industry will grow at incredible rates, the amount of aluminium in comparison to the above mentioned industries is still small and the alloys used in aerospace are to a great extent exclusive. In 2016, the overall aluminium demand is $71 \mathrm{Mt}$, and so a $24 \%$ rise may be expected by 2030. Another important feature taken from Figure 2 is that by 2030, recycled scrap will fulfil already $32 \%$ of $\mathrm{Al}$ demand, which represents a rise of $8 \%$ compared to 2010.

\subsection{Scrap Availability}

The lifespan of Al products is quiet uncertain, since $70 \%$ of all $\mathrm{Al}$ produced is still in use [3], however goods composed by aluminium have a relatively known lifespan. World of Aluminum, using global mass flow analysis, with an average lifespan and a standard deviation for each good, predicted the future scrap availability, including also collection rates [2]. This is particularly helpful to assess the sustainability of the recycling process, since the business as usual model (BAU) requires a higher demand of cast alloys than end of life scrap available. This topic has been addressed previously but only for specific industries, such as the automotive industry [4]. Nevertheless, collected scrap rarely comes only from one industry. Thus, 
analysing industries as independent leads to insightful but probably misleading results. Figure 2 shows an attempt to consider the total Al demand. Here, an absolute crossover is predicted by 2022, while other researchers' results, considering only ELV, point to 2018 [4]. The result obtained through data of World of Aluminum does not take into account three aspects: dilution, which would lead to an even higher offer of secondary Al, and thus anticipating the surplus. The second problem is that some industries, such as the packaging industry in USA, already developed their own recycling loops minimizing downgrading, which would delay the crossover. The last one concerns that in different parts of the world, aluminium is used differently, which means that the scrap composition varies throughout the world.

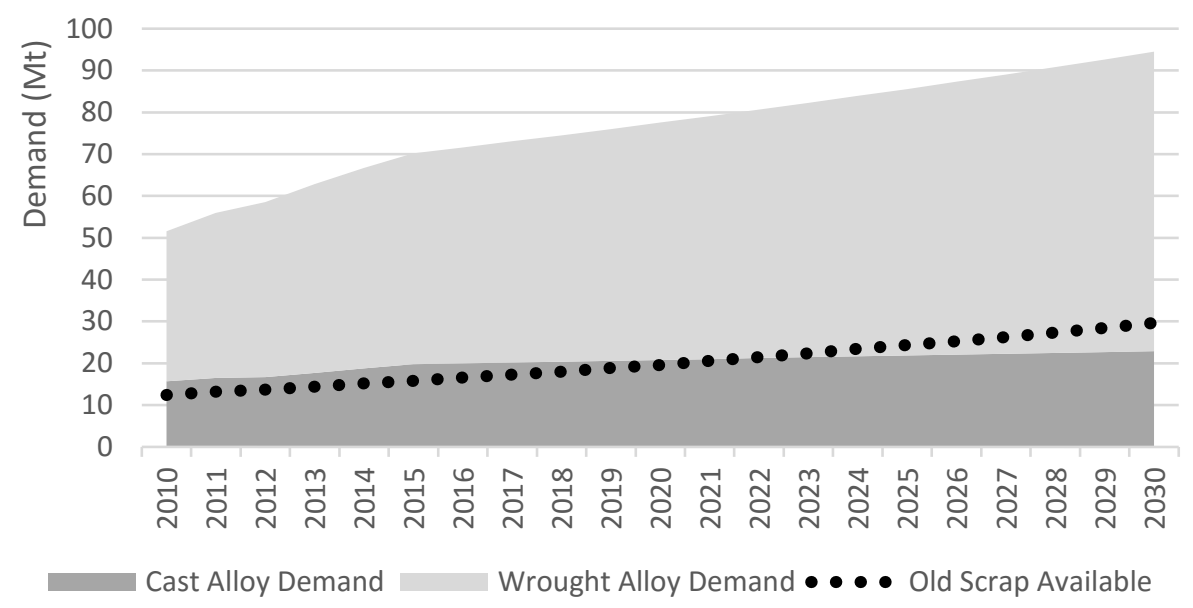

Fig. 2: Aluminum demand and old scrap availability.

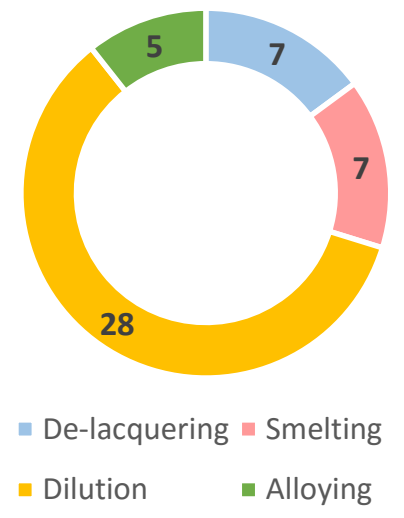

Fig. 3: Energy needs for recycling process $(\mathrm{GJ} / \mathrm{t})$.

Therefore this problem would take place in different times all over the countries, depending on how their economy makes use of aluminium. Nevertheless, rather than predicting the precise moment of the crossover, it is important to understand how to tackle this challenge.

\section{Recycling processes}

Al alloys are classified in two major groups, wrought and cast. Since the percentage of contaminants leads to lower ability to deformation, wrought alloys have much lower alloying elements share, on the other hand, as cast alloys do not need high deformability, have higher content of alloying elements [5]. Since most cast parts need further surface treatment, the addition of silicon gives also to these a higher machinability. This was well demonstrated in [6], and the suggested percentage to make the distinction is $5 \%$ (of $\mathrm{Si}$ ).

Aluminium recycling consumes much less energy than primary production. Around $140 \mathrm{MJ} / \mathrm{kg}$ are needed to produce primary $\mathrm{Al}$ ingots, mainly due to alumina refining $(24 \mathrm{MJ} / \mathrm{kg})$ and electrolysis $(111 \mathrm{MJ} / \mathrm{kg})$. The energy is obtained from fossil fuels and electricity mix, respectively [2].

The recycling process chain may be characterized as follows: collection, shredding, sorting (from other waste streams), de-lacquering, smelting, fluxing, dilution and addition of alloying elements. Collection, shredding and separation are very straight forward and energy-wise may be ignored. De-lacquering implies heating the old scrap up to $500^{\circ} \mathrm{C}$ and thus energy is required. In smelting, the scrap is heated up to $660^{\circ} \mathrm{C}$ in order to melt the mix. In fluxing, energy needs to be provided to help reactions with salts to take place and remove contaminants [7]. Since all scrap, from several alloys, is melted, the use of primary aluminium, in order to lower the contaminant's share, is needed. This dilution rate is around 20\% [4], meaning that per each ton entering the process, $200 \mathrm{~kg}$ of primary aluminium are added, so this energy must not be neglected. Then, there is the addition of alloying elements, which since the recycling is mostly aimed at cast alloys production, should mainly consist in the addition of silicon and/or magnesium. Adding up all energy needs for recycling, around $47 \mathrm{MJ} / \mathrm{kg}$ (Figure 3) is needed [2], which is $34 \%$ of primary $\mathrm{Al}$ production.

It is somehow shocking that $70 \%$ of the energy required for recycling could be avoided if each alloy was recycled in a closed-loop (dilution and alloying), thus needing only $10 \%$ of the energy required for primary $\mathrm{Al}$. 


\section{Sorting of Al alloys}

The solution for this problem, and the target to aim at, must always be closing the loop of each alloy series. However, current technology cannot compete economically with BAU. A solution that takes a step further on self-sustainability is sorting only certain alloys, or certain groups, such as wrought and cast.

Recent technology, like laser induced breakdown spectroscopy (LIBS), may help sorting plants to take this step. LIBS can identify the elements present in each piece of scrap [7]. This technology is still in a research phase as the throughput is still limited by computation time, even more if all the alloys are to be separated. However, an equipment able to separate wrought and cast would decrease considerably the effort for production of secondary wrought alloys.

Sorting would also decrease the need for dilution, since most cast parts have mainly silicon and/or magnesium, the weight of contaminants would be lower and thus less primary $\mathrm{Al}$ is needed in the recycling process. Alloying elements of wrought alloys are more diversified, nevertheless, their weight is relatively small, meaning that the dilution rates would either decrease or remain the same as nowadays for cast alloys. Although dilution rates depend on scrap composition and target output alloys, it is expected that these would decrease considerably. This is a further incentive to sorting, since less primary $\mathrm{Al}$ would be required, which means less costs for recycling. A statistical model which could link alloys and sectors, more accurate than the model used for Figure 1, may help estimate the required dilution rates when the sources of scrap are known, which in most cases they are, but this is out of the scope of this paper.

The decreasing need for primary $\mathrm{Al}$ during the recycling process is, by itself, an incentive to scrap sorting. Often the argument that sorting will lead to an overall decrease of primary Al consumption is also presented [1]. This would hold if aluminium demand was not increasing, and this is not the case for Al. Since the demand is rising, when decreasing dilution in recycling process, the total output of recycling will be smaller. In order to fulfil the demand, $\mathrm{Al}$ obtained directly from primary sources needs to be used, thus the need for primary aluminium remains constant as shown on Figure 4. Only with higher collection rates the need for primary $\mathrm{Al}$ will decrease, and this may as well be a side effect of sorting scrap, due to its higher value compared to mixed scrap.
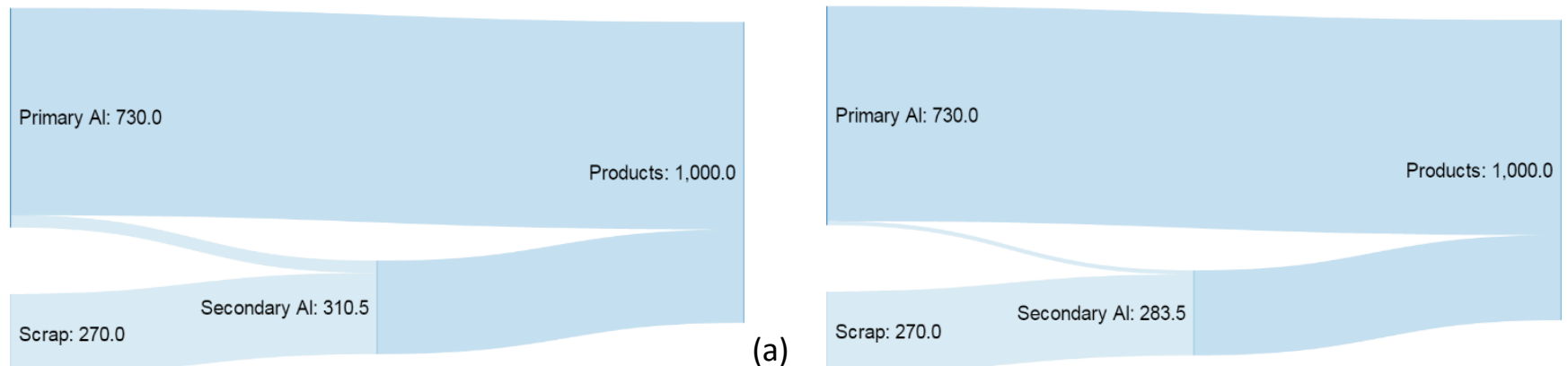

(b)

Fig. 4: Demand for primary Al remaining constant for 2030 (a) 15\% dilution rate; (b) 5\% dilution rate.

\section{Conclusions}

Being a step ahead of potential aluminium supply problems is crucial. Presently, we have the knowledge and technology to assess these problems and avoid them. Hence, different critical perspectives to anticipate these problems are urgent. This paper shows that Al demand is evolving rather fast and changes in industry approach are needed in order to allow aluminium to be as positive for environment as it can be. It also shows that although sorting is necessary to allow the sustainability of Al supply chain, this will not decrease the primary $\mathrm{Al}$ demand, if collection rates still do not increase. It is thus crucial to improve collection and simultaneously to develop efficient sorting of Al alloys.

Due to the proximity of the surplus, this cannot be fought with measures such as exploring designs which use less material or improving the collection rates, although this should be done in the long run. But rather introducing immediate changes in the recycling process, such as sorting alloys, and/or finding new uses for alloys with higher contamination rates. An industrial equipment capable of sorting will add a higher value to scrap, meaning that for such equipment to compete economically with BAU, its throughput does not need to be as high as typical current ones. Furthermore, the foreseen surplus of scrap, would decrease the value of non-sorted scrap and, on the other hand, separated scrap would keep its value, as the surplus of scrap would be avoided. 


\section{Acknowledgements}

The work here presented is included in the European project ShredderSort (Grant Agreement Nr. 603676, FP7 Theme ENV.2013.6.3-1; ENV.2013.6.2-3, collaborative projects). The authors wish to acknowledge the financial support of the European Commission.

\section{References}

[1] H. Hatayama, I. Daigo, Y. Matsuno, and Y. Adachi, "Evolution of aluminum recycling initiated by the introduction of next-generation vehicles and scrap sorting technology," Resources, Conservation and Recycling, vol. 66, pp. 8-14, 2012.

[2] Global Mass Flow Model 2013. (2016, May 4). [Online]. Available: http://www.world-aluminium.org/publications/.

[3] J. M. Allwood and J. M. Cullen, Sustainable materials: with both eyes open, Cambridge: UIT Cambridge, 2012.

[4] R. Modaresi and D. B. Müller, "The role of automobiles for the future of aluminum recycling," Environmental Science \& Technology, vol. 46, no. 16, pp. 8587-8594, 2012.

[5] D. Paraskevas, K. Kellens, W. Dewulf, and J. R. Duflou, "Environmental modelling of aluminium recycling: a Life Cycle Assessment tool for sustainable metal management," Journal of Cleaner Production, vol. 105, pp. 357-370, 2015.

[6] F. Margarido, C. A. Nogueira, R. Novais Santos, F. Durão, C. Guimarães, M. A. Trancoso, P. C. Oliveira, F. Pedrosa, and A. M. Gonçalves, "Evaluation of main aluminium alloys in non-ferrous fraction of auto-shredder recycling process," in M2D2015 - 6th Intern. Conf. on Mechanics and Materials in Design (Proc.), Ponta Delgada, Açores, Portugal, 2015, J. F. Silva Gomes, S. A. Meguid, Ed., pp. 2033-2038.

[7] G. Gaustad, E. Olivetti, and R. Kirchain, "Improving aluminum recycling: A survey of sorting and impurity removal technologies," Resources, Conservation and Recycling, vol. 58, pp. 79-87, 2012. 